\title{
O PROCESSO DE REFLEXÃO NO CONTEXTO DA AÇÃO: A PERCEPÇÃO DE EXECUTIVOS E EMPREENDEDORES
}

\section{REFLECTION PROCESS ON THE ACTION CONTEXT: PERCEPTION OF EXECUTIVES AND ENTREPRENEURS}

\section{EL PROCESO DE REFLEXIÓN EN EL CONTEXTO DE LA ACCIÓN: LA PERCEPCIÓN DE EJECUTIVOS Y EMPRENDEDORES}

\author{
Anielson Barbosa da Silva \\ Doutor em Engenharia de Produção pela Universidade Federal de Santa Catarina (UFSC). \\ Professor na Universidade Federal da Paraíba (UFPB) \\ Endereço: UFPB, Campus I, Departamento de Administração, Campus Universitário, CEP: 58059900. \\ João Pessoa, PB, Brasil \\ Telefone: (83) 3216-7492 \\ E-mail: anielson@uol.com.br

\section{Guilherme Diniz Araújo} \\ Mestre em Administração pelo Programa de Pós-Graduação em Administração (PPGA) da \\ Universidade Federal da Paraíba (UFPB) \\ Servidor Técnico-Administrativo do Instituto Federal de Permanbuco (IFPE). \\ Endereço: IFPE, Av. Prof. Luís Freire, n. 500, Cidade Universitária, CEP: 50740-540. Recife, PE, Brasil \\ Telefone:(81) 2125-1600 \\ E-mail: guilhermedadm@hotmail.com

\section{Matheus Dias Carrazzoni} \\ Bacharel em Administração pela Universidade Federal da Paraíba (UFPB) \\ Endereço: UFPB, Campus I, Departamento de Administração, Campus Universitário, CEP: 58059900. \\ João Pessoa, PB, Brasil \\ Telefone: (83) 3216-7492 \\ E-mail: matheuscarrazzoni@gmail.com
}

Artigo recebido em 11/09/2016. Revisado por pares em 21/11/2016. Reformulado em 10/12/2016. Recomendado para publicação em 10/12/2016. Publicado em 29/12/2016. Avaliado pelo Sistema double blind review.

\section{RESUMO}


Este artigo analisa o processo de reflexão de gestores que atuam em cargos executivos de médias e grandes empresas e de empreendedores. Foi realizada uma pesquisa qualitativa com executivos e empreendedores e os resultados revelaram significados envolvendo a relação entre reflexão e prática gerencial a partir das experiências, significados, barreiras, facilitadores e estímulos à reflexão no contexto organizacional. A reflexão apresenta-se como fator relevante para o processo de aprendizagem, resolução de problemas e geração de soluções criativas no contexto da ação profissional. O estudo traz contribuições para ampliar a compreensão sobre a dimensão subjetiva da prática gerencial.

Palavras-chave: Reflexão; Executivos; Empreendedores; Experiências; Prática gerencial.

\section{ABSTRACT}

This article examines the reflection process of managers who work in executive positions in medium and large enterprises and of entrepreneurs. A qualitative research was conducted with executives and entrepreneurs and the results revealed meanings involving the relationship between reflection and management practice related with experiences, meanings, barriers, facilitators and stimuli about the reflection in the organizational context. The reflection is presented as a relevant factor to the learning process, problem solving and generating creative solutions in the context of professional action. The study brings contributions to broaden the understanding of the subjective dimension of management practice.

Keywords: Reflection; Executives; Entrepreneurs; Experiences; Managerial practice.

\section{RESUMEN}

Este artículo analiza el proceso de reflexión de gestores que actúan en puestos ejecutivos de empresas medianas y grandes, y de emprendedores. Fue realizada una investigación cualitativa con ejecutivos y emprendedores, y los resultados revelan significados envueltos en la relación entre reflexión y práctica gerencial, desde las experiencias, significados, barreras, facilitadores y estímulos a la reflexión en el contexto organizacional. La reflexión se presenta como factor relevante para el proceso de aprendizaje, resolución de problemas y generación de soluciones creativas en el contexto de la acción profesional. El estudio trae contribuciones para ampliar la comprensión sobre la dimensión subjetiva de la práctica gerencial.

Palabras -clave: Reflexión; Ejecutivos; Emprendedores; Experiencias; Práctica gerencial. 


\section{INTRODUÇÃO}

A área de administração e negócios, desde seu surgimento, caracterizou-se por uma perspectiva racional de mundo e, por este motivo, buscou empreender esforços para alcançar as decisões ótimas. Partia-se da concepção de que o gestor poderia ter o domínio das informações de tal forma que alcançasse os melhores resultados. A obra de Simon (1957) constitui-se como um ponto de ruptura nesta visão, inserindo o conceito de Racionalidade Limitada e gerando uma nova agenda de pesquisas, que trouxe ao contexto da prática gerencial, novos elementos a serem analisados.

$\mathrm{Na}$ década de 1960 emergem estudos sobre aprendizagem no contexto das Organizações (EASTERBY-SMITH; BURGOYNE; ARAÚJO, 2001), e a obra Behavioral Theory of the Firm de Cyert e March impulsionou estudos subsequentes. Com o avanço das pesquisas surgem diferentes correntes: aprendizagem organizacional, organizações de aprendizagem, gestão do conhecimento e conhecimento organizacional (EASTERBY-SMITH; BURGOYNE, 2003). Emergem, também, diferentes níveis de análise: individual, grupal, organizacional e Inter organizacional. A discussão aqui empreendida envolve a perspectiva teórica da aprendizagem organizacional, por ser uma visão mais descritiva e acadêmica (VERA; CROSSAN, 2003), e exploram-se os níveis individual e grupal de análise.

Entende-se o contexto da prática gerencial como caracterizado por velocidade e exigências de diversos stakeholders, o que acaba acarretando uma inclinação à ação em detrimento da reflexão (MINTZBERG, 1990, 2010). Porém, ao passo que se desenvolvem as atividades gerenciais, novos problemas emergem e as velhas respostas parecem não se adequarem bem ao novo contexto, fazendo com que a aprendizagem seja fundamental para desenvolver novos cursos de ação. Contudo, a aprendizagem não se dá pela pura repetição da ação, mas pela relação dialógica entre ação e reflexão (MINTZBERG, 2006).

Os estudos envolvendo a aprendizagem de gestores, segundo Closs e Antonello (2010), indicam uma relevância crescente do processo reflexivo. Há, também, diferentes razões para a emergência de estudos sobre reflexão: (a) às vezes estamos inconscientes do nosso comportamento e suas consequências; (b) há, muitas vezes, uma lacuna entre o que dizemos e o que realmente fazemos; (c) a maioria das pessoas é tendenciosa na forma como 
busca informações que, por sua vez, produz uma percepção sobre a realidade; (d) embora as práticas intuitivas e experiências passadas indiquem pistas convincentes sobre como decifrar situações futuras, muitas vezes a nova situação apresenta-se em um contexto diferente (RAELIN, 2002).

O pensamento reflexivo permite ao indivíduo visualizar possíveis falhas, oportunidades novas e detalhes que não são percebidos quando há direcionamento em demasia sobre a ação (SOARES NETO, 2010). Assim, a perspectiva teórica aqui adotada é a da aprendizagem em ação, que entende a relevância da relação entre ação e reflexão, ao possibilitar uma revisão sobre as experiências e a construção de novos significados sobre as ações, gerando formas diferenciadas de visualizar e agir diante dos problemas atuais (McGILL; BROCKBANK, 2004; RIGANO; EDWARDS, 1998).

A pesquisa objetiva, portanto, analisar o processo de reflexão de gestores que atuam em cargos executivos de médias e grandes empresas e de empreendedores. As seções que seguem apresentam as bases teóricas sobre pensamento reflexivo e sua relação com a prática gerencial. Em seguida, descreve-se o percurso metodológico da pesquisa. Posteriormente, são apresentados e discutidos os resultados do estudo e as considerações finais.

\section{REFERENCIAL TEÓRICO}

Nesta seção discute-se o processo de reflexão na prática de profissionais que vivenciam o cotidiano gerencial. Inicia-se uma abordagem sobre pensamento reflexivo de maneira ampla, partindo de suas origens até sua inserção nos estudos organizacionais. Posteriormente, aprofunda-se a discussão acerca das implicações da reflexão na prática profissional de gestores.

\subsection{O PENSAMENTO REFLEXIVO}

O pensamento reflexivo remete à Grécia Antiga e ao método socrático de busca pelo conhecimento por meio do questionamento (DAUDELIN, 1996). A evolução do conhecimento e a emergência do método científico tornam a racionalidade uma exigência, sobretudo na prática profissional. Durante o século $\mathrm{XX}$, os pressupostos do positivismo e da 
racionalidade subjacente a este paradigma passam a ser questionados. É possível destacar duas abordagens principais sobre reflexão (HOYRUP, 2004) que emergem deste contexto: (a) reflexão, perspectiva mais instrumental, fruto dos trabalhos de John Dewey; e (b) reflexão crítica, mais voltada à emancipação do indivíduo em sociedade, baseada nos trabalhos de Jurgen Habermas.

Há, no entanto, muita confusão sobre as terminologias utilizadas em relação ao pensamento reflexivo. Alguns autores denominam reflexão crítica, outros falam sobre reflexão, alguns abordam em termos de pensamento crítico, há, ainda, os que discutam uma aprendizagem chamada de double loop, etc. (WOERKOM; NIJHOF; NIEUWENHUIS, 2002; WOERKOM, 2004). Todavia, para efeitos deste estudo, a definição adotada será a de Dewey $(1959$, p. 18) e dos estudos que adotam seu conceito: "ativo, prolongado e cuidadoso exame de toda a crença ou espécie hipotética de conhecimento, exame efetuado à luz dos argumentos que a apoiam e das conclusões que chega". Assim, entende-se que os pressupostos da reflexão crítica que emergem principalmente da perspectiva habermasiana não fazem parte do escopo deste estudo.

Ao discutir o pensamento reflexivo contido nas obras de Dewey, Rodgers (2002) apresenta quatro características do pensamento reflexivo: (a) este pensamento é fruto de um processo de busca por sentido a partir de uma experiência; (b) este é um tipo de pensamento sistemático, rigoroso, disciplinado e com raízes na forma de problematização científica; (c) a reflexão acontece a partir da interação; (d) a reflexão está intrinsecamente relacionada a atitudes, como estar de mente e coração abertos, ser objetivo e responsável, permitindo o crescimento de si e dos outros. A experiência parece, assim, ser um elemento central na caracterização do pensamento reflexivo. À experiência, Raelin (2001) acrescenta crenças e sentimentos. Estes elementos estão associados ao que se descreve como aprendizagem de alto nível (PELTIER; HAY; DRAGO, 2005).

Um fator que merece atenção para a abordagem de Dewey (1959) é o caráter individual do processo reflexivo, conforme ele expõe. A reflexão, em última instância, é um fator cognitivo. Todavia, o processo reflexivo pode ser catalisado pela participação em grupo (DAUDELIN, 1996; RODGERS, 2002; RAELIN, 2001; McGILL; BROCKBANK, 2004; HOYRUP, 2004). Porém, relações em grupo podem promover uma série de limitações à reflexão como, Revista Eletrônica de Estratégia \& Negócios, Florianópolis, v.9, n.3, set./dez. 2016. 
por exemplo, um comportamento defensivo ou reativo em relação aos sentimentos, crenças e percepções dos outros (HATTON; SMITH, 1995); ou individualismo, busca por redução de perdas, maximização de ganhos e minimização de sentimentos negativos (ARGYRIS; SCHÖN, 1996).

A reflexão ainda pode assumir diferentes tipologias. Hatton e Smith (1995) encontram, em sua pesquisa empírica, a reflexão descritiva, uma forma caracterizada por julgamentos pessoais; a reflexão dialógica, entendida como um embate entre a ação empreendida e os julgamentos pessoais, visando a explorar possíveis razões dos acontecimentos; e a reflexão crítica, que incorpora os elementos políticos, sociais e históricos envolvidos no evento. Reis (2011) cita outros três tipos: (a) auto-reflexão crítica, entendida como um questionamento de si enquanto ser social e em relação ao seu contexto amplo; (b) reflexividade prática, que envolve a consciência de si enquanto profissional; e (c) a reflexão pública ou organizacional, que se refere ao entendimento das inter-relações mais amplas entre os agentes e o contexto em que eles estão inseridos. Peltier, Hay e Drago (2005) acrescentam: (a) ação habitual, atividade não-reflexiva; (b) entendimento, busca por compreensão da tarefa, sem questionamento; (c) reflexão, busca por relação entre a atividade e experiências pessoais; e (d) reflexão intensiva, correspondente à consciência de por que eles pensam ou agem de tal forma em dada situação.

Considera-se, neste sentido, que apesar de suas diferentes definições, tipologias, e algumas limitações que apresenta, a reflexão assume um papel relevante na aprendizagem (HOYRUP, 2004).

Alguns estudos envolvendo a reflexão foram realizados no contexto do ensino, tais como o de Araújo (2014), que analisou as implicações da utilização de casos para ensino na prática reflexiva dos alunos do curso de administração, e o de Araújo et al. (2013), que objetivou analisar o desenvolvimento do pensamento reflexivo no processo de formação dos acadêmicos do Curso de Graduação em Administração da Universidade Federal da Paraíba.

Reis (2013) realizou um estudo envolvendo a prática reflexiva com o objetivo de evidenciar as contribuições da reflexão na aprendizagem dos processos de coaching de executivos. O ensaio teórico discute como os processos de reflexão crítica, da reflexão sobre 
a experiência e de como a articulação entre a prática reflexiva e os processos de coaching podem auxiliar nos processos de aprendizagem individual e organizacional.

A próxima seção discute com mais profundidade a reflexão no contexto da prática gerencial e os modelos de pensamento reflexivo.

\subsection{A REFLEXÃO NO CONTEXTO DA PRÁTICA GERENCIAL}

Um planejamento para um período de cinco anos parece não apresentar a mesma estabilidade e incertezas causadas pelas mudanças tecnológicas e sociais vivenciadas pelos gestores que limitam ou dificultam a predição de cenários (DAUDELIN, 1996). O pensamento reflexivo, enquanto instrumento para exame e avaliação da experiência e resolução de problemas, parece ser um fator relevante no contexto da prática gerencial (WOERKOM, 2004). Mas, de que forma ocorre a reflexão? Há tempo na prática gerencial para exercer este tipo elaborado de pensamento? Se sim, como ocorre o processo de reflexão?

Em estudo elaborado junto a gestores de ONG, Silva e Silva (2011) concluíram que a reflexão tem os seguintes significados para as suas vidas: (a) a reflexão faz parte da vida deles; (b) eles refletem durante as ações diárias; (c) o cargo leva-os a ampliar a capacidade de reflexão; (d) a reflexão decorre tanto da ação quanto da leitura; (e) o gerente reflete em ação, na interação com as pessoas e nas experiências do dia a dia; e (f) a reflexão é vista como ingrediente indispensável para o aprendizado. As experiências gerenciais são consideradas determinantes no desenvolvimento e uso da reflexão no contexto da prática gerencial, como preconizada por Silva (2009). Daudelin (1996) acrescenta que a reflexão pode ocorrer em atividades cotidianas, mesmo distante da ação, ao tomar banho, ao exercitar o corpo, etc., corroborando o que defende Raelin (2002, p. 19), ao afirmar que a "reflexão pode ocorrer antes, durante, ou depois da experiência".

Reforça-se o argumento de que a participação em grupo contribui para a catalisação do pensamento reflexivo. Existem alguns instrumentos que contribuem para a maximização da reflexão em grupo, tais como: (a) discussões de avaliação de desempenho; (b) sessões de aconselhamento; (c) terapia individual ou grupal; (d) reuniões de resolução de problemas; (e) sessões de revisão de projetos; (f) discussões informais com amigos e colegas; (g) entrevistas; (h) mentoria; (i) discussões de feedback (DAUDELIN, 1996). A relevância da Revista Eletrônica de Estratégia \& Negócios, Florianópolis, v.9, n.3, set./dez. 2016. 
reflexão em grupo decorre da possibilidade de dar e receber feedback, fazendo com que os indivíduos percebam as situações e argumentos de forma diferente e aceitando que seus pares possam exercer efeito sobre eles (RAELIN, 2001). Daudelin (1996, p. 42) complementa que, "quando reflexão toma lugar em pequenos grupos, ideias são geradas pelo compartilhamento de diferentes perspectivas".

Há, ainda, outras estratégias que as organizações podem adotar para estimular a prática reflexiva. Raelin (2001) cita cinco estratégias: (a) ações reflexivas; (b) construção de comunidades; (c) melhorias de processo; (d) equipes de aprendizagem; e (e) cultura de aprendizagem. Estas estratégias parecem ser incorporadas de alguma forma nos diferentes modelos de reflexão propostos para avaliar o processo reflexivo e a prática reflexiva. Pretende-se discutir estes modelos para iluminar as reflexões empíricas da pesquisa.

Um dos primeiros autores a propor um modelo sistemático sobre o processo reflexivo foi Dewey (1959). Seu modelo teórico apresenta cinco etapas e é básico para todos os modelos que serão apresentados a seguir. Em sua percepção, a reflexão inicia (1) quando o indivíduo elenca as possíveis soluções para resolver determinado problema. Em seguida (2), inicia-se um processo de intelectualização, quando o indivíduo percebe dificuldades em solucionar o problema e reconhece que outras respostas devem ser procuradas. Posteriormente, (3) o indivíduo elabora hipóteses que guiarão suas observações e operações. Parte-se, então, para (4) a elaboração de uma ideia final, que corresponde ao modelo a ser testado. E, por fim, (5) testa-se a hipótese. Estas cinco etapas, apesar de prescritivas, não são rígidas e não precisam ser seguidas uma após a outra.

Dois problemas decorrem do modelo proposto por Dewey (1959): (a) é puramente conceitual e não tem fundamento empírico; (b) sua perspectiva parece não incorporar a participação de outros como catalisadores da reflexão. O modelo de Daudelin (1996) parte da mesma perspectiva de Dewey (1959), mas, apesar de incorporar o grupo e citar algumas formas de como a interação com outros pode contribuir para o processo, não aprofunda a relação entre o pensamento reflexivo e seu modelo de reflexão. Considera-se, neste sentido, que os modelos que se seguem parecem responder melhor a uma perspectiva tanto individual quanto grupal da reflexão. 
Ao formular sua concepção de aprendizagem, Schön (1983; 2000) incorpora a perspectiva de reflexão de Dewey (1959). Para o autor, os profissionais sabem muito mais do que podem informar sobre sua prática, pois grande parte do conhecimento que eles põem em ação é tácito. Este tipo de conhecimento é inerente à ação, e definido como conhecimento-em-ação. A externalização desse conhecimento ocorre a partir de um processo que tem suas bases na reflexão. Schön $(1983 ; 2000)$ insere, assim, o conceito de reflexão-em-ação, que corresponde à compreensão das motivações e influências que determinam o curso de ação. Ao refletir-em-ação, o indivíduo pode alterar seu percurso e o resultado final da atividade, o que não ocorre quando ele apenas conhece-em-ação. Outra etapa apresentada pelo autor é a reflexão sobre a ação, que ocorre após o término da atividade. Nesta etapa, o indivíduo não pode mais alterar o curso da ação, mas extrai, da experiência, a aprendizagem necessária para interpretar problemas futuros e agir. O modelo de Schön (1983; 2000) é composto, portanto, de: (a) ação; (b) conhecer-em-ação; (c) refletirem-ação; (d) refletir sobre a ação.

Ao desenvolver sua proposta de aprendizagem em ação, McGill e Brockbank (2004) fazem uma releitura do modelo de Schön (1983). Os autores discutem as quatro etapas do pensamento reflexivo propostas por Schön em termos de dimensões: (1) ação, que envolve conhecimento-em-ação, conhecimento em uso e a própria ação; (2) reflexão-em-ação, conforme descreve Schön (1983; 2000); (3) descrição da reflexão-em-ação, que consiste em um relato individual sobre a reflexão-em-ação; (4) a reflexão sobre a ação, em que o grupo discute os relatos individuais elaborados na etapa 3; e (5) reflexão sobre a reflexão-sobre-aação, que é uma dimensão agregada pelos autores à perspectiva de Schön, visando a descrever o momento em que os indivíduos estabelecem suas próprias reflexões acerca de todo o processo reflexivo anterior, gerando implicações para as suas práticas.

Por fim, vale a pena citar a pesquisa de Roglio (2006), que discutiu o executivo reflexivo. Um dos pressupostos de sua pesquisa é que a prática reflexiva do executivo fundamenta-se na inter-relação entre os pensamentos crítico, criativo e introspectivo. De maneira básica, definem-se os três tipos de pensamento da seguinte forma: (a) o pensamento crítico corresponde ao pensar e repensar sobre a situação, os envolvidos e o ambiente, e sobre os fatores políticos, históricos e sociais referentes em interação; (b) o 
pensamento introspectivo envolve a capacidade de compreender a influência dos valores, experiências, atitudes, emoções e intuições pessoais em sua relação com a situação; e (c) o pensamento criativo abrange as possibilidades que se abrem ao observar a situação de maneira sistêmica, e à visualização de soluções alternativas para os problemas vivenciados.

A partir das reflexões sobre as bases teóricas que fundamentam o estudo, parte-se para a discussão do percurso metodológico, que possibilitou a entrada dos pesquisadores no campo e a verificação empírica da discussão teórica até aqui empreendida.

\section{PERCURSO METOdOLÓGICO}

A análise do processo reflexivo de executivos e empreendedores ocorreu a partir dos relatos de experiências e percepções sobre a prática profissional destes sujeitos, conforme propõe Merriam (2009). Utilizou-se, portanto, uma abordagem qualitativa, entendida como um conjunto de técnicas que permite compreender fenômenos sociais (MORGAN; SMIRCICH, 1980). Considerando os objetivos e as limitações referentes a tempo, espaço e sujeitos da pesquisa, optou-se por um estudo qualitativo básico, que possibilita (a) descrever, interpretar e compreender; e (b) identificar padrões recorrentes que podem ser tematizados ou categorizados (MERRIAM, 2009).

O público selecionado para participar da pesquisa envolveu executivos e empreendedores que atuam em empresas localizadas na capital de um Estado do Nordeste brasileiro. Foram selecionados seis gestores de empresas de médio e grande porte, e dez empreendedores de empresas de pequeno e médio porte que desenvolvem suas atividades em diferentes setores (indústria, comércio e serviços).

Os sujeitos entrevistados apresentam experiências bastante diversificadas. Foram entrevistados gestores com experiência profissional variando entre oito e trinta e um anos de atuação em cargos de gestão, seja como executivos ou como empreendedores. A diversidade é um fator determinante para o estudo, uma vez que permite a reflexão sobre experiências no contexto da ação dos profissionais pesquisados. A seleção foi feita por conveniência, utilizando os critérios de disponibilidade de tempo, interesse em participar da pesquisa e relatar experiências de situações profissionais, e da percepção sobre o processo de reflexão.

Revista Eletrônica de Estratégia \& Negócios, Florianópolis, v.9, n.3, set./dez. 2016. 
A coleta de dados foi realizada por meio de entrevistas que ajudaram a captar percepções, sentimentos e entendimentos tácitos (GRAY, 2012), e por não ser possível observar, dadas as limitações, os comportamentos dos envolvidos em tempo real (MERRIAM, 2009). O instrumento de coleta consistiu em um roteiro semiestruturado com catorze perguntas, envolvendo a trajetória profissional dos gestores, a relação entre reflexão e prática gerencial, e a articulação entre os pensamentos crítico, introspectivo e criativo destes profissionais. As entrevistas foram gravadas e transcritas para a posterior análise.

A análise dos dados seguiu as etapas propostas por Minayo (1998), consistindo em (a) ordenação dos dados; (b) classificação dos dados; e (c) análise final dos dados. Na primeira etapa de análise, realizou-se uma leitura do protocolo das entrevistas com o objetivo de identificar as categorias e as unidades de significados na percepção dos pesquisados. Assim, utilizou-se o termo Emp para caracteriza o empreendedor, e Ex para caracterizar o executivo de médias e grandes empresas, seguido de um número representado por algarismos romanos de I a VI para os executivos e de I a X para os empreendedores.

Em seguida foi realizada a classificação dos dados, agrupando os diversos relatos dos gestores em categorias de análise, relacionando-os às dimensões de análise propostas, permitindo estabelecer um diálogo entre as categorias teóricas e as categorias empíricas. A análise final dos dados foi realizada com o objetivo de revelar os significados do estudo em consonância com objetivo de pesquisa, buscando, assim, compreender como executivos de empresas de grande porte e empreendedores de pequeno e médio porte desenvolvem e utilizam a reflexão em sua prática profissional. Os resultados finais da análise são discutidos na seção que segue.

\section{RESULTADOS DA PESQUISA}

A apresentação dos resultados desta pesquisa está estruturada em três partes. $\mathrm{Na}$ primeira discute-se a relação entre a reflexão e a prática gerencial a partir das experiências, significados, barreiras e estímulos à reflexão no contexto organizacional. Na subseção seguinte explora-se a articulação entre os pensamentos crítico, introspectivo e criativo 
presentes na prática de executivos e empreendedores pesquisados. Por fim, apresenta-se um quadro com a síntese dos resultados da pesquisa.

\subsection{REFLEXÃO E PRÁTICA GERENCIAL}

Esta seção discute a relação entre reflexão e prática gerencial a partir de quatro categorias: (a) significado de reflexão, buscando captar o entendimento dos gestores sobre o conceito e a relevância para a sua prática profissional; (b) barreiras à reflexão no contexto organizacional, entendidas como fatores que podem reduzir o potencial da aprendizagem por meio da reflexão; (c) relação entre reflexão e aprendizagem gerencial, indicando como a reflexão pode mediar a relação entre experiência e aprendizagem; (d) estímulos à reflexão nas organizações, visando aos fatores do cotidiano da prática gerencial que podem contribuir para o desenvolvimento, e a utilização da reflexão no contexto do trabalho.

\subsubsection{Significado de reflexão}

Ao relatarem os significados que a reflexão tem para a sua prática profissional, os gestores trouxeram aspectos vinculados aos conceitos de reflexão-na-ação e reflexão sobre a ação, conforme discutem Schön (1983; 2000) e McGill e Brockbank (2004). O Emp. V aponta para a reflexão-na-ação ao relatar que a "reflexão é uma recapitulação daquilo que você está fazendo, quando eu faço uma coisa, eu reflito se aquilo que eu fiz realmente vai surtir efeito, converso com algumas pessoas, pergunto, o que o pessoal acha". Pode-se caracterizar esta definição como reflexão-na-ação porque, no processo de tomada de decisão, o gestor busca outras opiniões que possibilitem mudar o curso da ação enquanto ela ocorre, servindo para "remodelar o que nós fazemos enquanto nós estamos fazendo" (HOYRUP, 2004, p. 448). O Emp. VII também compartilha esta perspectiva de reflexão-naação. Outro executivo considera que a reflexão é sempre posterior à ação, tendo implicações para as ações futuras: "eu acho, assim, é a gente olhar pra dentro e avaliar alguns comportamentos. Eu penso reflexão como algo sempre posterior às ações" (Ex. V).

Os gestores também parecem ponderar outros fatores mais amplos, tais como os possíveis cenários, conforme discute Daudelin (1996), que serão encontrados quando a decisão for tomada. O relato do Ex. II retrata esta percepção da reflexão: "Você termina traçando na sua cabeça os caminhos, 'se eu posso ir por A, B, C...' [...] Então, acho que Revista Eletrônica de Estratégia \& Negócios, Florianópolis, v.9, n.3, set./dez. 2016. 
refletir pra mim é isso: avaliar, ponderar, pensar quais são as consequências daquilo ali que você está fazendo, aí você vai fazer". O Ex. III ainda acrescenta a necessidade de pensar, analisar e avaliar como passos para a reflexão. O Emp. III expõe a relevância de avaliar as vantagens e desvantagens e o impacto que as ferramentas podem ter para a organização: "quais são as opções disponíveis, vantagens e desvantagens dessas, o custo financeiro e o custo processual de cada ferramenta né?". Estes relatos evidenciam a relevância da reflexão para o contexto destes profissionais, remetendo à incerteza relacionada ao ambiente de negócios, que acarreta uma necessidade de refletir sobre as experiências passadas e as possibilidades futuras.

Há, ainda, implicações para os indivíduos, quando emerge uma dimensão introspectiva e experiencial dos significados de reflexão a partir dos relatos dos gestores. Um dos discursos explicita a experiência como fator significativo para o cotidiano destes profissionais: "eu acho que é chegar às soluções com mais maturidade, mesmo que leve mais tempo" (Emp. III). A maturidade pode ser entendida como um processo de ganho de experiência, e isto faz com que os gestores repensem suas ações, gerando implicações pessoais e para a prática futura: "hoje você pode tá refletindo de um jeito e amanhã você pode fazer uma reflexão diferente em função de um comportamento, em função até de uma preocupação que você tem..." (Ex. I).

Neste sentido, para a prática profissional dos gestores, a reflexão significa a possibilidade de compreender a partir da experiência e dos fatores individuais, as possibilidades de alterar o curso das ações e pensar nas vantagens e desvantagens da decisão para ações futuras, visando a alcançar resultados mais satisfatórios.

\subsubsection{Barreiras ao desenvolvimento da reflexão}

Dois fatores parecem ser centrais para retardar o processo de reflexão na prática gerencial. O primeiro é a velocidade e as exigências decorrentes do ambiente organizacional, fazendo com que, às vezes, se reflita pouco sobre as possibilidades que envolvem uma decisão. O segundo ponto é o conflito entre áreas da organização.

Quanto ao ritmo das decisões, os gestores explicitam que a necessidade de decidir e agir rapidamente faz com que você reflita menos sobre as oportunidades que se oferecem. Revista Eletrônica de Estratégia \& Negócios, Florianópolis, v.9, n.3, set./dez. 2016. 
O discurso de Emp. VII fundamenta esta análise: "às vezes atrapalha, porque você não tem tempo pra tá pensando o que vai fazer a propaganda de um produto, promoção pra poder lançar". O Ex. II também entende esta velocidade como barreira. Para ele, a tomada de decisão, às vezes, envolve informação, leitura, estudo, mas nem sempre o ambiente permite este aprofundamento na análise, o que reduz o potencial da reflexão.

Conforme discutido na seção 4.1.1, a reflexão na prática gerencial tem, na experiência, um fator determinante. Porém, os relatos acima parecem apontar para incertezas que não encontram respostas na experiência, exigindo diálogo, outras fontes de informação, etc. Esta barreira parece estar relacionada a uma perspectiva temporal e à deficiência em refletir-na-ação. Apoiar-se em coaches, consultores externos ou parceiros durante o processo de tomada de decisão pode ser benéfico para levá-los a refletir-na-ação (McGILL; BROCKBANK, 2004). Buscar estabelecer iniciativas de fomento ao pensamento reflexivo também pode contribuir para que este processo se torne natural, o que pode acontecer durante reuniões para resolução de problemas, sessões de aconselhamento e feedback, etc. (DAUDELIN, 1996).

Por outro lado, é interessante discutir que o fator tempo tem um aspecto contextual envolvido. O Emp. VIII relata que esta realidade acaba sendo benéfica pelo seu ramo de atuação: "isso aí é a realidade da nossa vida hoje. Hoje nós vivemos uma vida do fast-food né? Da internet, hoje tudo é muito rápido, ninguém pode perder tempo, então eu vejo a questão aí só de se organizar". Ofertar o serviço de fast-food está intrinsecamente relacionado a uma realidade de respostas rápidas. Todavia, deve-se considerar que, neste ramo e para este público-alvo, ofertam-se produtos padronizados e que exigem poucas mudanças, e impõem poucos problemas, fazendo com que o gestor coloque-se poucas vezes em situações que necessita refletir de forma mais ampla em torno de aspectos da prática gerencial, com níveis de complexidade mais elevados. O potencial de utilização da reflexão deste gestor pode ser reduzido em função da realidade, ou ele pode ter aprendido a refletirem-ação. Capturar estas diferenças, todavia, não faz parte do escopo desta pesquisa.

O conflito entre áreas da mesma organização pode ser outro empecilho. Não se encontram relatos dos empreendedores sobre isto, em função das limitações de tamanho de suas organizações e, também, porque eles exercem diversas funções gerenciais Revista Eletrônica de Estratégia \& Negócios, Florianópolis, v.9, n.3, set./dez. 2016. 
simultaneamente, reduzindo o conflito interdepartamental. Todavia, o Ex. $\mathrm{V}$ relata que as visões diferentes na organização reduzem o potencial de reflexão:

Quando chegam algumas coisas no financeiro, o operacional, a área industrial, tem uma mente muito pra frente, muito avançada e quer muito, e o financeiro controla porque está dentro da função dele. Então, a burocracia que a gente sente aqui, muito, é isso... não só sou eu, não. Os gerentes aqui também têm essa limitação de ter projetos e às vezes esses projetos não andarem na velocidade que se tem vontade porque a outra área barra. (Informação verbal, Ex. V).

Estes conflitos podem ser entendidos como conflitos políticos, e não de tarefas. Conflitos políticos reduzem o potencial de aprendizagem e inovação dentro de uma organização, enquanto conflitos de tarefa podem maximizar a aprendizagem (CLERCQ; MENGUC; AUH, 2008). Este tipo de conflito pode limitar o potencial reflexivo dos profissionais, à medida que os gestores ficam menos preocupados em alcançar os objetivos organizacionais e mais interessados em obter benefícios individuais ou departamentais. Pode-se afirmar, neste sentido, que o estímulo aos conflitos de tarefa podem beneficiar a organização e possibilitam a exposição de membros de diferentes áreas na indicação de formas e visões diferentes, problematizando a decisão e gerando um ambiente em que os profissionais criam uma visão compartilhada em torno da melhor solução para o todo. Para isto, o número de participantes no processo de reflexão se amplia, o que, para Daudelin (1996), aumenta o tempo para se tomar uma decisão, mas maximiza os resultados do processo. Assim, o conflito político entre áreas pode prejudicar a reflexão e as decisões, mas estimular o conflito de tarefa pode ser um fator determinante para a reflexão dos gerentes.

\subsubsection{Reflexão e aprendizagem}

A reflexão é considerada mediadora para a aprendizagem (PELTIER; HAY; DRAGO, 2005). Para os gestores, a reflexão traz diversas implicações para a aprendizagem sobre as suas atividades cotidianas. O Emp. III revela que a reflexão estimula a ponderação e a trabalhar com diferentes perspectivas (opiniões de outros). Outras implicações da reflexão envolvem a possibilidade de aprender a partir dos erros, e aumento da velocidade no poder de reflexão por meio da experiência.

Ao vivenciar uma experiência abre-se, aos gestores, a possibilidade de avaliar os erros e desenvolver um portfólio para decisões futuras. Há, assim, uma relação entre a Revista Eletrônica de Estratégia \& Negócios, Florianópolis, v.9, n.3, set./dez. 2016. 
prática, que gera experiência; e a reflexão, que pode maximizar a aprendizagem. O relato de Ex. V é exemplar para esta análise: "quando você reflete numa situação que você passa por ela de novo, você já sabe como agir. Mas se você não refletiu antes, não sabe como agir novamente. Você continua naquela 'e agora, o que eu vou fazer?'”. Esta análise relaciona-se com o que defende Raelin (2001, p. 20), ao afirmar que "nossa aprendizagem pode ser contínua, além do nosso ponto de captura". Repensar os erros e aprender sobre eles assume, também, papel determinante para o cotidiano gerencial (WOERKOM, 2004).

Outros fatores presentes nos relatos dos gestores ajudam a compreender os vínculos entre reflexão e aprendizagem, e envolvem a necessidade de externalizar entendimentos sobre as ações; a automação da tomada de decisão, que decorre da prática cotidiana; e oportunidades de reflexão crítica, que emergem do fazer gerencial em relação ao amplo contexto em que os profissionais estão inseridos.

Sobre a necessidade de externalização, o Ex. VI afirma que, a partir da interação com as pessoas, com os operários, com o presidente da empresa e com pessoas do ambiente externo da organização, é possível externar pensamentos e obter feedback, melhorando, assim, a decisão pela adoção de diferentes pontos de vista. O relato deste executivo relaciona-se com o pensamento de Raelin (2001, p. 21), quando defende que "nossos pensamentos são constantemente remodelados quando convertemos em linguagem e colocamos para fora na presença de outros".

Vivenciar experiências parece catalisar o pensamento reflexivo. Para Ex. III, com o passar dos anos, a reflexão "passa a ser automática mesmo (...) mas esse pensamento reflexivo se ajusta às situações. Portanto, essas situações é que vão determinar o pensamento sobre elas e a decisão". Raelin (2001) também parece contribuir para compreender este processo, ao defender que, apesar de a aprendizagem passada e a intuição serem importantes, o contexto influenciará, em última instância, na decisão tomada. Todavia, o portfólio e a reflexão sobre ele contribuem para a aprendizagem destes profissionais.

Há, também, uma dimensão de auto avaliação inserida neste contexto. Ao buscarem aprender, os gestores refletem não apenas sobre suas tarefas, mas sobre si mesmos. 0 
relato do Emp. VIII remete a esta forma de aprendizagem: "fazer essa auto avaliação e isso [...traz] benefícios tanto físico, como social, psicológico e porquê não dizer até espiritual né?". Assim, no processo de auto avaliação, o gestor busca melhorar não só os resultados das decisões, mas as implicações que aquilo pode trazer para ele. Há uma dimensão dialógica e crítica contida neste tipo de reflexão, pois os indivíduos começam a perceber a decisão para além de suas implicações diretas (WOERKOM; NIJHOF; NIEUWENHUIS, 2002).

Portanto, para esses gestores, a aprendizagem ocorre por um processo desenvolvido na prática, a partir do qual o indivíduo adquire experiências e tem como mediadora, a reflexão. O grupo pode ser um catalisador neste processo, fazendo com que os indivíduos externem suas opiniões e recebam outros pontos de vista, chegando, assim, a ver pontos de convergência e divergência que conduzam a uma decisão mais favorável ao amplo contexto.

\subsubsection{Estímulos à reflexão nas organizações}

Em seus relatos, os gestores apontam para os facilitadores do pensamento reflexivo dentro das organizações. Para eles, o fortalecimento do trabalho em equipe é o catalizador do processo de reflexão, ocorrendo sob duas formas: (a) reuniões em equipe para compartilhar pontos de vista; e (b) desenvolvimento de uma cultura que permita reflexão e aprendizagem. Estes aspectos também são apontados na literatura sobre aprendizagem e reflexão.

Os empreendedores Emp. I e Emp. IV concordam sobre a relevância de reuniões em equipe. Para o Emp. I, é importante reunir-se com a equipe para estimular a reflexão dos outros indivíduos, por que a reflexão coletiva contribui para o crescimento das pessoas, como ilustra o seguinte trecho da entrevista: "quero uma equipe que cresça comigo" (Emp. 1). Essa abertura para diálogo com a equipe parece indicar aceitação ao fornecimento e recebimento de feedback com a equipe. Estas reuniões parecem favorecer alguns dos facilitadores discutidos por Woerkom, Nijhof e Nieuwenhuis (2002), tais como compartilhamento de visão, desafio ao pensamento do grupo, pedido de feedback e compartilhamento do conhecimento. Como forma de maximizar a qualidade das reuniões, o Emp. IV apresenta um tema comum a ser discutido: 
Pronto, normalmente a gente faz assim, é, antes de toda reunião, a gente têm um texto, as pessoas leem um texto. Então, cada um depois vai falar sobre aquele texto, o que achou daquele texto entendeu? Então a gente faz com todas as pessoas pra que elas participem da reunião e a gente consiga perceber o que ela sente em relação àquilo, aquele tema proposto (Emp. IV).

A utilização de um texto, para este empreendedor, possibilita discutir uma ideia central, facilitando o processo de resolução de problemas, geração de ideias e o debate em torno delas. É relevante, contudo, que este processo ocorra em uma organização cuja cultura contribua para a sua promoção. O Ex. $\mathrm{V}$ ressalta que trabalhar de portas abertas, escutar os profissionais da organização, deixá-los à vontade para fornecer ideias e propostas de melhoria pode contribuir para a abertura a uma cultura que estimule o pensamento reflexivo na organização. Raelin $(2002$, p. 68) afirma que uma cultura de reflexão possibilita "desafiar constantemente sem medo de retaliação". Porém, desenvolver esta cultura não é fácil, já que ela permite o desafio ao status quo, e nem sempre os gestores estão dispostos a abrir mão de suas posições privilegiadas para isto. Deve-se considerar, neste sentido, os prós e contras do desenvolvimento desta visão, entendendo que ela é benéfica ao pensamento reflexivo e pressupondo que ele é relevante para a prática gerencial.

\subsection{O PENSAMENTO REFLEXIVO DOS EXECUTIVOS E EMPREENDEDORES}

Esta dimensão é amplamente influenciada pela tese de Roglio (2006) e visa a discutir a articulação entre os pensamentos crítico, introspectivo e criativo. A partir das experiências dos gestores busca-se discutir: (a) como eles compreendem o contexto amplo de maneira sistêmica, permitindo que visualizem as situações de maneira crítica; (b) como os sentimentos, valores pessoais e experiências passadas são considerados no processo decisório para ponderar e repensar as situações e a si próprios; e (c) de que forma estes profissionais podem pensar em soluções diferentes diante dos problemas que se apresentam. O pressuposto subjacente a esta seção é de que, ao articular estes três tipos de pensamento, os profissionais podem tomar decisões que sejam benéficas aos indivíduos, à organização e à sociedade.

\subsubsection{O desenvolvimento e a utilização do pensamento crítico}

Revista Eletrônica de Estratégia \& Negócios, Florianópolis, v.9, n.3, set./dez. 2016. 
A utilização do pensamento crítico, para os gestores pesquisados, ocorre a partir da percepção de mudança e da necessidade de fazer diferente. Por vezes, o pensamento crítico toma forma a partir da análise de decisões errôneas, levando a uma nova percepção da situação. A manifestação deste tipo de pensamento decorre de arrependimento, reinterpretação, diálogo que gera diferentes perspectivas sobre uma determinada prática, ou busca por parâmetros que possibilitem fazer uma crítica interna à organização e gerar melhorias.

Para o Emp. VI, um exemplo de utilização do pensamento crítico sobre uma decisão tomada foi assim descrito: "situações de demissão de funcionários assim [...] eu já chamei até um funcionário pra trabalhar de volta. Me arrependi, que não é bom, o funcionário já vem com outra (...) achando que é alguma coisa". Neste sentido, a crítica parece contribuir para uma forma de aprendizagem a partir dos erros, conforme discutem Woerkom, Nijhof e Nieuwenhuis (2002) e Silva e Silva (2011).

Já para o Ex. III, a crítica refere-se a reinterpretar as situações vivenciadas, utilizando o conhecimento e a experiência de situações anteriores e buscando estabelecer relação com a situação atual: "é uma forma de você interpretar aquelas situações, avaliar e apontar o que pode ser ponto forte, ponto fraco, o que é positivo, o que não, dentro daquela situação". O pensamento crítico, neste sentido, é entendido como a capacidade de redefinir suposições (ROGLIO, 2006).

Todavia, este tipo de pensamento só tem abertura quando o indivíduo se propõe a viver um desafio constante em sua prática: a busca por melhoria. O relato de Ex. II é exemplar: "eu acho que o que leva é, pelo menos pra mim, a questão do desafio. (...) Eu acho que a disposição que a pessoa tem de querer fazer uma coisa melhor". Organizações que estão inseridas em ambientes pouco desafiadores ou que não estimulam ações desafiadoras e a melhoria contínua como partes do cotidiano organizacional não criam ambientes propícios ao pensamento crítico. É este ambiente que possibilita a articulação entre diferentes perspectivas, o dar e o receber feedback, o diálogo reflexivo que contribui para o repensar da prática e a geração de novidades: "tem determinadas coisas que [...] são simples, mas a grande maioria, por exemplo, você pode discutir com as pessoas e tentar 
encontrar... às vezes vai implantar uma solução, assim, mas aí entra um pouquinho do outro que melhora aquela solução" (Informação verbal, Ex. I).

Torna-se relevante, também, mapear o cenário onde a organização está inserida. Um dos gestores cita a análise sobre a concorrência como prática a ser explorada para desenvolver a autocrítica: "aí a gente procurou também até saber em outras empresas, como é que fazia aquele mesmo trabalho que a gente fazia, se as pessoas estavam trabalhando de modo semelhante" (Ex. II). Esta perspectiva relaciona-se com insegurança ou, nos termos de Woerkom, Nijhof e Nieuwenhuis (2002), de baixa auto eficácia. O gestor parece não saber exatamente quais impactos aquela prática pode gerar, ou se o trabalho está correto. Então, busca utilizar outras organizações como parâmetro. Woerkom, Nijhof e Nieuwenhuis (2002) apontam que a auto eficácia é um fator significativo na reflexão do trabalhador. Talvez buscar observar os outros e estabelecer autocrítica, conforme relata o Ex. Il ajude no desenvolvimento das crenças de auto eficácia profissional e, como consequência, amplie sua capacidade de reflexão.

\subsubsection{O desenvolvimento e a utilização do pensamento introspectivo}

Ao serem questionados sobre o uso do pensamento introspectivo no cotidiano, os gestores demonstram um forte apelo à orientação religiosa no processo de tomada de decisão. Outro ponto que é discutido pelos gestores é a dinâmica do trabalho dentro das equipes e a abertura às diferentes opiniões, gerando um clima de empatia, que leva ao repensar de conceitos enraizados (taken-for-granted).

O Emp. VII relata a influência da espiritualidade sobre seus valores e prática profissionais: "na minha introspeç̧ão eu sempre busco orientação de Deus, todo ato que eu vou fazer. Então, é aí onde entra a parte espiritual onde é a ênfase da vida, é você buscar realmente orientação de Deus" (Emp. VII). Já o Emp. IX explora a espiritualidade em termos de equilíbrio: "tem que ter equilíbrio, essa palavra resume né, equilíbrio entre a área espiritual, não é? Você tem que tá, ter o seu norte, ter Deus como tudo na sua vida, fazer a sua parte, mas confiando na vontade dele e entregando a ele as tuas decisões". Estes discursos explicitam uma dimensão menos racional do trabalho do gestor, uma conversa consigo, com os valores religiosos desenvolvidos ao longo da vida e que são incorporados 
nas experiências do trabalho, oportunizando um equilíbrio entre a necessidade de alcance dos resultados e as crenças inerentes à ética religiosa.

A influência da espiritualidade também é evidenciada em Roglio (2006). A autora identifica o pensamento introspectivo como resgate da intuição e da arte no processo decisório, o desenvolvimento da espiritualidade, e uma busca pelo equilíbrio entre a vida pessoal e a vida profissional. Outros gestores colocam, ainda, este tipo de pensamento como um exercício da empatia, de buscar compreender as diferenças dos outros em relação ao eu. O Ex.VI exemplifica esta percepção: "dentro desse pensamento você expressa para as pessoas o porquê daquelas suas decisões e você pode ouvir também porque as pessoas decidiram de uma maneira diferente... elas podem ter princípios diferentes dos seus".

O pensamento introspectivo, neste sentido, enquanto busca por compreensão dos próprios valores e crenças, parece ser desenvolvido em grande parte na relação com o outro, na busca pelos valores morais da espiritualidade. Há, no entanto, uma dimensão social envolvida no pensamento introspectivo, à medida que os indivíduos passam a entender as implicações de sua visão de mundo no contexto em que estão inseridos.

O pensamento introspectivo emerge, assim, da prática profissional e da percepção dos outros agentes, da busca por respostas que o pensamento racional não consegue fornecer, de uma busca constante por equilíbrio, ou como define Senge (1990), uma busca por desenvolvimento de Maestria Pessoal.

\subsubsection{O desenvolvimento e a utilização do pensamento criativo}

Conforme já discutido, o pensamento reflexivo tem como uma de suas principais contribuições a abertura para repensar sobre a prática, possibilitando alcançar novas formas de solucionar os problemas no contexto organizacional. Para os gestores entrevistados, a articulação do pensamento criativo com os demais tipos de pensamentos (crítico e introspectivo) permite alcançar insights, pensar em planos alternativos, visualizar as necessidades e oportunidades de mudança, e é desenvolvido por meio da análise sobre a concorrência e a sinergia entre diferentes áreas da organização em direção a um resultado satisfatório para toda a organização, mas é, muitas vezes, limitado pelo ambiente externo. 
Os empreendedores traduzem o pensamento criativo em termos de insights, luz para a resolução de problemas, busca por soluções alternativas ou improviso. Já os executivos visualizam a necessidade da mudança: "a gente desenvolve esse pensamento criativo com a necessidade mesmo, nas situações que a gente está vivendo, a gente vê que não dá pra agir da mesma forma que a gente vem fazendo em situações semelhantes. Então isso nos força a pensar, né?" (Ex. II). Estas noções estão alinhadas com os resultados da pesquisa realizada por Roglio (2006, p. 179), ao entrevistar executivos de programas de MBA americanos, ao afirmar que a concepção de pensamento criativo está alinhada com a ideia de criatividade: "as suas concepções sobre o pensamento criativo convergem para a identificação de soluções originais para os desafios organizacionais".

Observar o ambiente organizacional de forma sistêmica também contribui, e analisar a concorrência parece ser um impulsionador do pensamento criativo:

A gente procura ver como outras pessoas resolveram tais riscos, ou como preveniram. Isso dá ideias de como fazer, ou adaptar para a nossa realidade, para aquele ambiente, o inédito muitas vezes não vem de uma coisa que nunca ninguém inventou, pelo menos não lá no nosso mundo. Vem de uma coisa que alguém já usou, mas a gente adéqua a uma realidade. Então, é isso, os nossos desafios do nosso dia-a-dia nos exigem essa criatividade (Informação verbal, Ex. II).

No trabalho em equipe, a sinergia entre áreas da organização fica implícita nos discursos do Ex.VI, que identifica a equipe como catalisadora, possibilitando visualizar diferentes perspectivas e, assim, chegar a uma solução compartilhada e diferente daquelas individuais como já ressaltadas anteriormente. O relato do Ex. I, a seguir, demonstra como diferentes áreas podem contribuir de forma significativa para um resultado compartilhado:

Qualquer desenvolvimento aqui... A pessoa desenvolveu, mas antes do produto ser produzido, ele senta com todas as pessoas da área de processo produtivo de cada segmento e discute com as pessoas, tolerância, as especificações, e as limitações, porque às vezes têm limitações. O cara vai falar assim "esse produto não dá". Nem precisa entrar com ele, já morre aqui. Você nem continua. (Informação verbal, Ex. I).

Há de se considerar, por fim, a existência de uma limitação, dependendo do setor ou serviço que a organização presta. Em organizações que prestam serviços ao governo, as limitações referentes à burocracia podem tolher a liberdade para o uso do pensamento criativo: "não tenho muita coragem de inovar, de criar, de pensar em coisas diferentes, pra Revista Eletrônica de Estratégia \& Negócios, Florianópolis, v.9, n.3, set./dez. 2016. 
não sair daquela ordem que eu me dispus a manter. Isso é um pecado. Eu considero um pecado. Não é uma rotina minha. Eu não uso isso" (Ex. V).

Deve-se, assim, atentar para o uso do pensamento criativo e identificar estratégias para fomentar seu desenvolvimento, considerando as limitações do ambiente da ação gerencial. O trabalho em equipe, o compartilhamento de ideias, e a interconexão com os pensamentos introspectivo e crítico parecem contribuir para o estabelecimento de soluções diferentes, sobretudo porque permitem enxergar os problemas de forma diferente.

\subsection{SÍNTESE DOS RESULTADOS}

Os resultados da pesquisa são sintetizados no Quadro 1. Pode-se visualizar, nesta síntese, as dimensões de análise e categorias propostas. A dimensão reflexão e prática gerencial é composta por quatro categorias: (a) significado de reflexão; (b) barreiras à reflexão; (c) reflexão e aprendizagem; e (d) estímulos à reflexão. Já a dimensão pensamento reflexivo compõe-se de outras três categorias: (a) pensamento crítico; (b) pensamento introspectivo; e (c) pensamento criativo.

Quadro 1 - Síntese das semelhanças e diferenças entre o processo reflexivo de Executivos e Empreendedores Paraibanos.

\begin{tabular}{|c|c|c|c|}
\hline Dimensão & Categoria & Empreendedores & Executivos \\
\hline \multirow{4}{*}{$\begin{array}{l}\text { Reflexão e } \\
\text { Prática } \\
\text { Gerencial }\end{array}$} & $\begin{array}{l}\text { Significado de } \\
\text { reflexão }\end{array}$ & $\begin{array}{l}\text { - Recapitular sobre aquilo que } \\
\text { está fazendo; } \\
\text { - Parar para pensar sobre } \\
\text { alguma coisa; } \\
\text { - Criação de um inventário das } \\
\text { possibilidades para maior } \\
\text { segurança na decisão; } \\
\text { - Ganho de maturidade. }\end{array}$ & $\begin{array}{l}\text { - Construção de cenários; } \\
\text { - Análise e avaliação da situação; } \\
\text { - Avaliação de comportamentos e } \\
\text { introspecção. }\end{array}$ \\
\hline & $\begin{array}{l}\text { Barreiras à } \\
\text { reflexão }\end{array}$ & - Falta de tempo pra pensar. & $\begin{array}{l}\text { - Visão de curto prazo; } \\
\text { - Conflitos entre áreas da } \\
\text { organização. }\end{array}$ \\
\hline & $\begin{array}{l}\text { Reflexão e } \\
\text { aprendizagem }\end{array}$ & $\begin{array}{l}\text { - Decisões mais ponderadas e } \\
\text { com soluções mais embasadas; } \\
\text { - Auto avaliação; } \\
\text { - Análise de pontos fortes e } \\
\text { fracos relacionados à decisão. }\end{array}$ & $\begin{array}{l}\text { - Referencial para futuras decisões; } \\
\text { - Necessidade de externalização; } \\
\text { - Automação da tomada de } \\
\text { decisão. }\end{array}$ \\
\hline & $\begin{array}{l}\text { Estímulos à } \\
\text { reflexão }\end{array}$ & $\begin{array}{l}\text { - Reuniões semanais com a } \\
\text { equipe. }\end{array}$ & $\begin{array}{l}\text { - Criação de uma cultura de } \\
\text { reflexão na organização. }\end{array}$ \\
\hline
\end{tabular}


Pensamento Reflexivo

\section{Pensamento}

Criativo

Pensamento

Crítico

cil

Pensamento

Introspectivo
- Crítica do próprio modelo de pensar;

- Voltar atrás em uma decisão;

- Modificar algumas ações para que haja sucesso nas decisões.

- "Insight";

- Estímulo aos colaboradores a pensar criativamente e resolver problemas;

- Ter um plano $b$ para qualquer situação.

- Conceitos enraizados;• Aspectos do jeitinho brasileiro para tomar decisões;

- Espiritualidade.
- Comparação com outras experiências;

- Necessidade de mudança e inovação;

- Exercício de coerência;

- Adoção de diferentes perspectivas;

- Análise da concorrência.

- Necessidade de mudança;

- Limitação referente à demanda;

- Análise sistemática da concorrência;

- Trabalho em equipe e sinergia entre áreas da organização.

- Conceitos enraizados;

- Empatia (saber falar e ouvir);

- Espiritualidade.

Fonte: Elaborado pelos autores (2015).

Os significados vinculados a cada uma das categorias de análise indicam mais diferenças do que semelhanças entre a percepção de empreendedores e gerentes sobre como a reflexão está presente na prática gerencial. Uma análise conjunta dos resultados do estudo podem subsidiar o estabelecimento de ações para estimular o desenvolvimento do pensamento e da prática reflexiva.

\section{CONSIDERAÇÕES FINAIS}

A reflexão apresenta-se como fator relevante para o processo de aprendizagem, resolução de problemas e geração de soluções criativas no contexto organizacional. As experiências, quando passam pelo processo reflexivo, conduzem os gestores à ampliação das alternativas, visualização de diferentes cenários e maior confiança em si para tomar decisões. O apoio da equipe e a realização de reuniões, a abertura ao feedback e o desenvolvimento de uma cultura que permita a reflexão parecem catalisar a reflexão dos gestores.

A análise das dimensões do pensamento reflexivo (pensamentos crítico, introspectivo e criativo) de forma desarticulada é um desafio, uma vez que estão intimamente relacionados, tornando-se difícil, às vezes, categorizar os relatos de maneira a aprofundar a análise. Todavia, os relatos indicam que a crítica se estabelece por um recurso a decisões 
passadas e ao reordenamento da situação presente, visualizando a situação de maneira mais ampla e seus impactos sistêmicos. O pensamento introspectivo manifesta-se, sobretudo, por meio da espiritualidade e das oportunidades de visualizar o comportamento do outro, um sentimento de empatia. Esta concepção é um retorno a uma forma artística de desenvolver a prática profissional, fugindo ao racionalismo que, por vezes, não consegue alcançar as dimensões tácitas do conhecimento exigido a determinadas tarefas. A criatividade manifesta-se no desenvolvimento de planos alternativos, na busca por resolução de problemas de maneira diferente, à necessidade de mudar, e aos empecilhos que se apresentam e exigem uma nova abordagem.

Uma vantagem da pesquisa empreendida foi compreender como os gestores enxergam a relação entre reflexão e prática gerencial. Todavia, este estudo partiu do pressuposto subjacente a outros já desenvolvidos sobre o pensamento reflexivo, que defendem a efetividade deste para o processo de aprendizagem gerencial e ganhos para os indivíduos, organização e sociedade. Porém, para aferir o real impacto da reflexão sobre a prática gerencial, estudos quantitativos podem ser realizados, comparando o desempenho de gestores no processo de tomada de decisão e a forma como eles entendem que a reflexão influencia em sua ação profissional.

Para futuros estudos, recomenda-se a realização de uma pesquisa que traga à tona os fatores relacionados à reflexão crítica, utilizando como referencial autores que discutam a reflexão sob uma perspectiva habermasiana. Outros estudos podem ajudar a revelar os elementos políticos, sociais e culturais subjacentes à reflexão, possibilitando discutir a participação de outros agentes neste processo. A influência das decisões sobre os demais trabalhadores da organização, a abertura ao diálogo e a possibilidade de participação aos afetados pelas decisões tomadas no contexto organizacional são fatores que podem ser considerados em estudos como estes.

O estudo traz contribuições para ampliar a compreensão sobre a dimensão subjetiva da prática gerencial. A racionalidade dá lugar, assim, a processos intuitivos e conhecimento tácito adquirido pela experiência mediada pela reflexão.

\section{REFERÊNCIAS}

Revista Eletrônica de Estratégia \& Negócios, Florianópolis, v.9, n.3, set./dez. 2016. 
ARAÚJO, G.D. As Implicações da utilização do Método de Caso para Ensino na Prática Reflexiva de alunos de Graduação em Administração. 165 f. Dissertação (Mestrado em Administração) - Programa de Pós-Graduação em Administração, UFPB, João Pessoa - PB, 2014.

ARAÚJO, G.D.; SILVA, A.B.; LIMA, T.B.; BISPO, A.C.K.A. O desenvolvimento do pensamento reflexivo no curso de administração da universidade federal da paraíba.

Revista Reflexão e Ação, Santa Cruz do Sul, v.21, n. esp., p.149-176, jul./dez. 2013.

ARGYRIS, C.; SCHÖN, D. Organizational Learning II: theory, method, and practice. New York: Addison Wesley, 1996.

CLERCQ, D. D.; MENGUC, B.; AUH, S. Unpacking the relationship between an innovation strategy and firm performance: The role of task conflict and political activity. Journal of Business Research, v. 62, p.1046-1053, 2008.

CLOSS, L. Q.; ANTONELLO, C. S. Aprendizagem transformadora: integrando a reflexão crítica na formação gerencial. Revista Gestão Org., nov. 2010.

DAUDELIN, M. W. Learning from experience through reflection. Organizational Dynamics, v. 24, n.3, p. 36-49, Winter 1996.

DEWEY, J. Como pensamos: como se relaciona o pensamento reflexivo com o processo educativo (uma reexposição). 4. ed. Tradução de Haydée Camargo Campos. São Paulo: Nacional, 1959.

EASTERBY-SMITH, M.; BURGOYNE, J. Introduction: Watersheds of Organizational Learning and Knowledge Management. In: EASTERBY-SMITH, M.; BURGOYNE, J. (Org.). The Blackwell handbook of organizational learning and knowledge management. Malden/USA, 2003, p. 1-15.

EASTERBY-SMITH, M.; BURGOYNE, J.; ARAÚJO, L. (Coord.). Aprendizagem organizacional e organização de aprendizagem: desenvolvimento na teoria e na prática. São Paulo: Atlas, 2001.

GRAY, David E. Pesquisa no Mundo Real. 2 ed. Porto Alegre: Penso, 2012.

HATTON, N.; SMITH, D. Reflection in teacher education: towards definition and implementation. Teach. Teach. Educ., v.1, n.2, p.33-49, 1995.

HOYRUP, S. Reflection as a core process in organisational learning. Journal of Workplace Learning, v. 7-8, n. 16, p. 442-454, 2004.

MCGILL, I.; BROCKBANK, A. The Action Learning Handbook: Powerfull Tecniques for education, professional development and training. RoutledgeFalmer. New York, 2004.

MERRIAM, S. B. Qualitative research: a guide to design and implementation. San Francisco: Jossey-Bass, 2009. 
MINAYO, M. C. O desafio do conhecimento: pesquisa qualitativa em saúde. 5 ed. São Paulo: Hucitec; Rio de Janeiro: Abrasco, 1998.

MINTZBERG, H. The manager's job: folklore and fact. Haward Business Review, Boston, v. 6, n. 8, p. 163-170, mar./abr., 2006.

MINTZBERG, H. Managing: desvendando o dia a dia da gestão. São Paulo: Bookman, 2010.

MORGAN, G.; SMIRCICH, L. The case for qualitative research. Academy of Management Review, v. 5, n. 4, p. 491-500, 1980.

PELTIER, J. W.; HAY, A.; DRAGO, W. The reflective learning continuum: Reflecting on reflection. Journal of Marketing Education, v. 27, n. 3, p. 250-263, 2005.

RAELIN, J. A. Public reflection as the basis of learning. Management Learning, Thousand Oaks, vol. 32, n. 1, p. 12-30, 2001.

RAELIN, J. A. "I don't have time to think!" versus the art of reflective practice. Reflections, v. 4, n. 1, p. 66-79, Fall 2002.

REIS, G. G. Da experiência ao aprendizado: a prática reflexiva como recurso no processo de coaching de executivos. Revista de Carreiras e Pessoas, v. 3, n. 3, p. 34-48, 2013.

REIS, D. G. O papel da reflexão na aprendizagem gerencial. In: ANTONELLO, C.S.; GODOY, A.S. (Org.) Aprendizagem Organizacional no Brasil. Porto Alegre: Bookman, 2011, p. 353-380.

RIGANO, D.; EDWARDS, J. Incorporating reflection into work practice: A case study. Management Learning, 1998.

RODGERS, C. Defining Reflection: another look at John Dewey and reflective thinking. Teachers College Record, v. 104, n. 4, p. 842-866, June 2002.

ROGLIO, K. D. O executivo reflexivo: arquiteto e facilitador de novas configurações organizacionais. Florianópolis, 2006. 275 f. Tese (Doutorado em Engenharia de Produção) Programa de Pós Graduação em Engenharia de Produção, Universidade Federal de Santa Catarina.

SCHÖN, D. A. Educando o profissional reflexivo: um novo design para o ensino e a aprendizagem. Porto Alegre: Artes Médicas Sul, 2000.

SCHÖN, D. A. The reflective practitioner: how professionals think in action. New York: Basic Books, 1983.

SENGE, P. A quinta disciplina. São Paulo: Best Seller, 1990.

SILVA, L. B; SILVA, A. B. A reflexão como mediadora da aprendizagem gerencial em organizações não governamentais. RAM. Revista de Administração Mackenzie (Online), v. 12, p. 55-89, 2011.

SILVA, A. B. Como os gerentes aprendem? São Paulo: Saraiva, 2009. 
SIMON, Herbert A. (1956) Rational choice and the structure of the environment.

Psychological Review, v. 63, p. 261-273, 1957.

SOARES NETO, A. Aprendizagem de auditores fiscais no contexto da prática profissional. 2010. 166f. Dissertação (Mestrado em Administração)-Universidade Federal da Paraíba, João Pessoa, 2010.

VERA, D.; CROSSAN, M. Organizacional Learning and Knowledge Management: toward an integrative framework. In: EASTERBY-SMITH, M.; BURGOYNE, J. (Org.). The Blackwell handbook of organizational learning and knowledge management. Malden/USA, 2003, p. 122-141.

WOERKOM, M. van. The concept of critical reflection and its implications for human resource development. Advances in Development Human Resources, v. 6, n. 2, p. 178-192, 2004.

WOERKOM, M. van; NIJHOF, W. J.; NIEUWENHULS, L. F. M. Critical reflective working behaviour: a survey research. Journal of Eurpean Industrial Training, v. 26, n. 8, p. 375-383, 2002. 